Article

\title{
Selection of Aptamers Specific for DEHP Based on sSDNA Library Immobilized SELEX and Development of Electrochemical Impedance Spectroscopy Aptasensor
}

\author{
Qi Lu ${ }^{1}$, Xixia Liu ${ }^{1,2,3, *}$, Jianjun Hou ${ }^{1,2,3, *}$, Qiuxue Yuan ${ }^{3}$, Yani Li $^{1}$ and Sirui Chen ${ }^{1}$ \\ 1 Hubei Key Laboratory of Edible Wild Plants Conservation and Utilization, College of Life Sciences, Hubei \\ Normal University, Huangshi 435002, China; lq18271691835@163.com (Q.L.); yqx1816752719@163.com (Q.Y.);

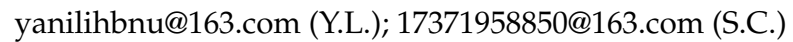 \\ 2 Hubei Engineering Research Center of typical wild vegetable Breeding and Comprehensive Utilization \\ Technology; Hubei Normal University, Huangshi 435002, China \\ 3 National Demonstration Center for Experimental Biology Education, Hubei Normal University, \\ Huangshi 435002, China \\ * Correspondence: liuxixia@hbnu.edu.cn (X.L.); jjhou@mail.hzau.edu.cn (J.H.)
}

Received: 30 December 2019; Accepted: 25 January 2020; Published: 9 February 2020

\begin{abstract}
A selection of aptamers specific for di(2-ethylhexyl) phthalate (DEHP) and development of electrochemical impedance spectroscopy (EIS) aptasensor are described in this paper. The aptamers were selected from an immobilized ssDNA library using the systematic evolution of ligands by exponential enrichment (SELEX). The enrichment was monitored using real-time quantitative PCR (Q-PCR), and the aptamers were identified by high-throughput sequencing (HTS), gold nanoparticles (AuNPs) colorimetric assay, and localized surface plasmon resonance (LSPR). The EIS aptasensor was developed to detect DEHP in water samples. After eight rounds of enrichment, HTS, AuNPs colorimetric assay, and LSPR analysis indicated that four aptamers had higher binding activity, and aptamer 31 had the highest affinity $(\mathrm{Kd}=2.26 \pm 0.06 \mathrm{nM})$. The EIS aptasensor had a limit of detection (LOD) of $0.103 \mathrm{pg} / \mathrm{mL}$ with no cross-reactivity to DEHP analogs and a mean recovery of $76.07 \%$ to $141.32 \%$ for detection of DEHP in water samples. This aptamer is novel with the highest affinity and sensitivity.
\end{abstract}

Keywords: electrochemical aptasensor; ssDNA library immobilized SELEX; aptamer; di(2-ethylhexyl) phthalate; water sample

\section{Introduction}

Di(2-ethylhexyl) phthalate (DEHP) is a kind of plasticizer that has toxic effects associated with its action as an androgen antagonist. It can lead to endocrine disorders and the reduction of human immunity [1,2]. However, DEHP is widely used as an additive to food packaging materials, which leads to its accumulation in food exceeding the national standards for its ability to migrate from food packaging to drinking water $[3,4]$. Therefore, it is necessary to continuously and effectively monitor the residue of DEHP.

At present, the methods for DEHP detection include analytical instrumentation, immunoassay, and biosensor. The commonly applied methods use analytical separation instruments. The limit of detection (LOD) of these methods is $0.05-10 \mathrm{mg} / \mathrm{L}$ for high-performance liquid chromatography (HPLC) [5-7], 0.01-0.1 ng/mL for high performance liquid chromatography-mass spectrometry (HPLC-MS) [8], 0.008-356 $\mu \mathrm{g} / \mathrm{mL}$ for gas chromatography-mass spectrometry (GC-MS) [9], 
and $0.21 \mu \mathrm{g} / \mathrm{L}$ for mass spectrometry [10]. However, these methods are expensive, time-consuming, and have high LOD, which inhibit their application in the field for on-spot rapid detection. Alternatively, enzyme-linked immunosorbent assay (ELISA) has a LOD of $4.2 \mathrm{pg} / \mathrm{mL}$ [11], while the LOD is $3.9 \mathrm{pg} / \mathrm{mL}$ [12] for electrochemical aptasensor, $0.5 \mathrm{pg} / \mathrm{mL}$ for quantum dot aptasensor [13], and $8 \mathrm{pM}$ for surface-enhanced raman spectroscopy (SERS) aptasensor [14]. The obvious advantages of these rapid-detection techniques are that they are fast, low-cost, and exhibit high selectivity and sensitivity in monitoring trace DEHP in samples. The quality of recognition molecules is critical for establishing these rapid-detection methods. However, the required antibodies used in ELISA always have issues, such as requiring more time for preparing monoclonal antibody and uneven quality for polyclonal antibody [15]. Therefore, aptamers may be the most suitable recognition molecules for the detection of DEHP.

An aptamer is a single-strand DNA (ssDNA) or RNA selected from DNA or RNA library using the systematic evolution of ligands by exponential enrichment (SELEX) [16]. A specific aptamer has many advantages, including short preparation time, a wide range of targets, and easy labeling and modification $[17,18]$, which make it more appropriate than an antibody as a recognition molecule in biosensors [19]. There are several reports on the application of aptamers for the detection of small molecules, such as ractopamine [20], aflatoxin B1 [21], chloramphenicol [22], and ochratoxin A (OTA) [23]. Researchers have also successfully constructed aptamer-based biosensors to detect DEHP. Han [12] reported a group-specific aptamer to detect phthalic acid esters using an electrochemical biosensor, although the distinction of DEHP from phthalic acid esters was difficult. Later, a truncated aptamer specific for DEHP was reported by Lim [13], which also enabled establishing a quantum dot aptasensor. However, this detection technology was complex and was thus not used to detect real samples in their research. An aptasensor [14] based on SERS has also been developed with a LOD of $8 \mathrm{pM}$. However, this method included a series of procedures involving magnetic particles and silver nanoparticles with silica. Therefore, it is desirable to select aptamers that are specific for DEHP and design a direct DEHP detection method with improved sensitivity and affinity.

In this work, we isolated an aptamer specific for DEHP from immobilized ssDNA library and developed a direct electrochemical impedance spectroscopy (EIS) aptasensor. First, ssDNA with strong binding activity to DEHP was enriched by eight rounds of SELEX. Then, high-throughput sequencing (HTS), gold nanoparticles (AuNPs) colorimetric assay, and localized surface plasmon resonance (LSPR) were conducted to characterize the aptamer of highest affinity. Finally, an EIS aptasensor was established to directly detect DEHP residue in water samples.

\section{Results and Discussion}

\subsection{Selection of Aptamers Specific for DEHP Based on ssDNA Immobilized SELEX}

A key step for aptamer selection involves monitoring the enrichment of the ssDNA library. An early report [24] has suggested that real-time PCR is the most simple and effective method to monitor the selection of aptamers specific for small molecules or other targets. Therefore, in this research, we used real-time PCR to monitor the enrichment of aptamers specific for DEHP. The analytical curve of quantitative PCR (Q-PCR) is shown in Figure 1A. The correlation coefficient $R^{2}$ was 0.9935 , indicating a good linear correlation between $\mathrm{Ct}$ (the corresponding cycle when the fluorescence reaches the fluorescence threshold) and log (concentration of template ssDNA). The retention rate (Figure 1B) was calculated according to the $\mathrm{Ct}$ value and analytical curve, and the calculation formulas of retention rate are mentioned in the supplementary information. The retention rate increased gradually from the first to the fourth round of selection but decreased from the fifth to the seventh round of selection due to the counter selection, which excluded most of the nonspecific binders. Further, from the fifth to the eighth round, the retention rate increased gradually because of specific gradual enrichment of the aptamer library. Particularly, the retention rate was higher in the eighth round of selection than in all 
the other rounds, indicating that the library was enriched specifically. Thus, the selection was stopped in the eighth round.

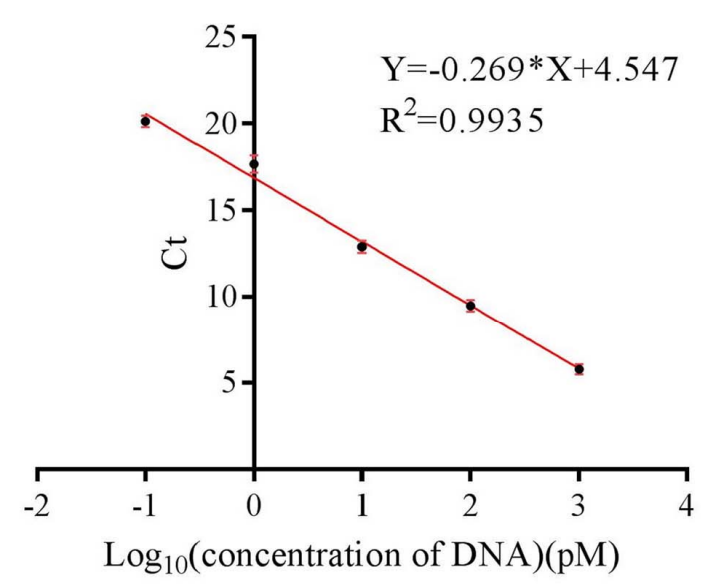

A

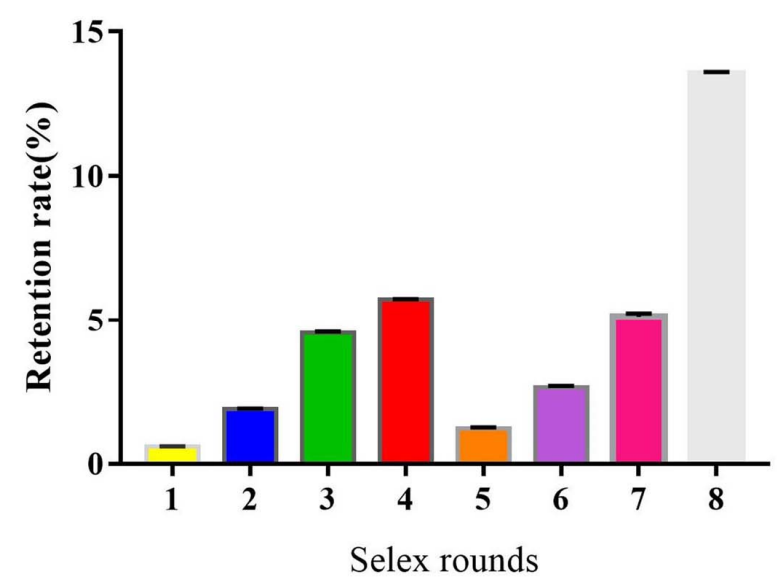

B

Figure 1. Q-PCR monitoring the process of selection. (A) The quantitative analytical curve of Q-PCR, (B) the retention rate for each round of selection.

\subsection{High-Throughput Sequencing and Sequence Analysis of the Enriched Library}

The enriched library of the eighth round was sequenced by HTS technology, which showed a total of 20,000 different sequences. Compared with the commonly used method (cloning to a vector) [25], HTS is an effective method to obtain rich sequence information in a short time. Then, Three hundred sequences with a higher frequency of occurrence were selected, and the random area of 40 base sequences was analyzed by clustal X2 (Figure S1). Then, one hundred and twenty-nine sequences with the highest rate of homology were obtained by TreeView tool analysis (Figure S2), and their sequences were measured online on the mfold analysis platform to display one-ring region structure or more. Ninety-six sequences with several ring regions $(\geq 2)$ were selected to identify binding activity. Each aptamer was truncated to 58 bases by removing 11 bases each from the $5^{\prime}$ and $3^{\prime}$ end constant regions from the original sequences ( 80 bases) for the next step.

\subsection{Establishment of Gold Nanoparticles Colomertric Assay to Identify Active Aptamers}

The binding activity of candidate aptamers (96 aptamers) was initially determined using AuNPs, and the result is presented in Figure 2. The AuNPs were dispersed with the protection of the aptamer. When the added DEHP combined with the aptamer, the AuNPs lost the protection and aggregated due to the impact of the highly concentrated salt solution. The dispersed AuNPs appeared wine-red, and the aggregated AuNPs appeared blue. The characteristic peaks moved from $520 \mathrm{~nm}$ to $620 \mathrm{~nm}$.

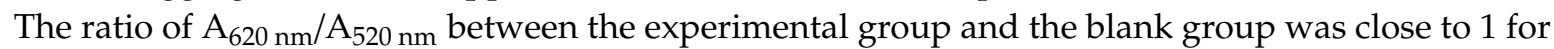
most of the aptamers with low binding activity to DEHP. Interestingly, four aptamers had a ratio of $>1.1$, indicating that the $A_{620} \mathrm{~nm} / A_{520} \mathrm{~nm}$ value of the experimental group was greater than that of the blank group. This also showed the affinity between DEHP and aptamers, with a large number of combined complexes being produced. This is the first study to report a label-free, fast, and time-saving method for identification of the binding activity of aptamers specific for DEHP from an enriched library with a AuNPs colometric assay. 


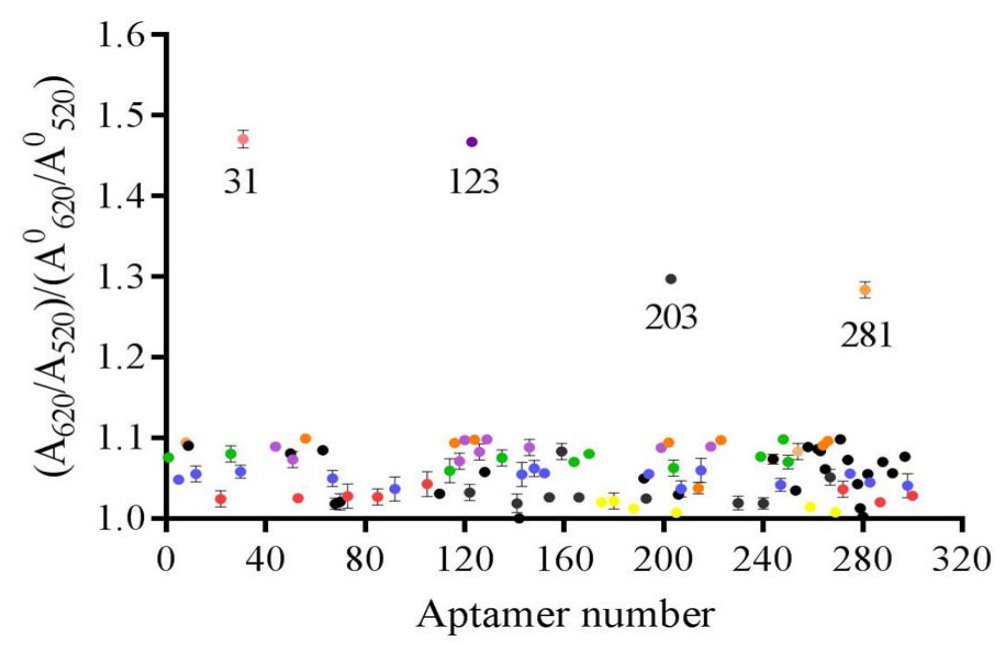

Figure 2. Preliminarily selection of active aptamers using the AuNPs colomertric assay.

\subsection{Characterization of Active Aptamers}

Generally, electrochemistry [26], fluorescence [27], colorimetry [28], LSPR [29], and chemiluminescence [30] are applied to confirm the affinities of aptamers. LSPR is a label-free, money- and time-saving method for identification of aptamer affinity. The binding curves for four active aptamers in LSPR are presented in Figure 3. The signals increased when the aptamer concentration increased, indicating that the aptamer could bind with the DEHP on the surface of the chip. The detailed sequence information and affinity constants are noted in Table 1. Aptamer 31 had the highest affinity with $\mathrm{Kd}=2.26 \pm 0.06 \mathrm{nM}$, which was lower than that for all reported aptamers specific for small molecules. In a previous report, the affinity constants were beyond $10 \mathrm{nM}$ for most aptamers [31,32]. Generally, LSPR is a powerful and sensitive tool for elucidation of the interaction between DNA and small molecules [33]. Therefore, aptamer 31, whose secondary structure is shown in Figure 4, was selected to develop DEHP detection methods.
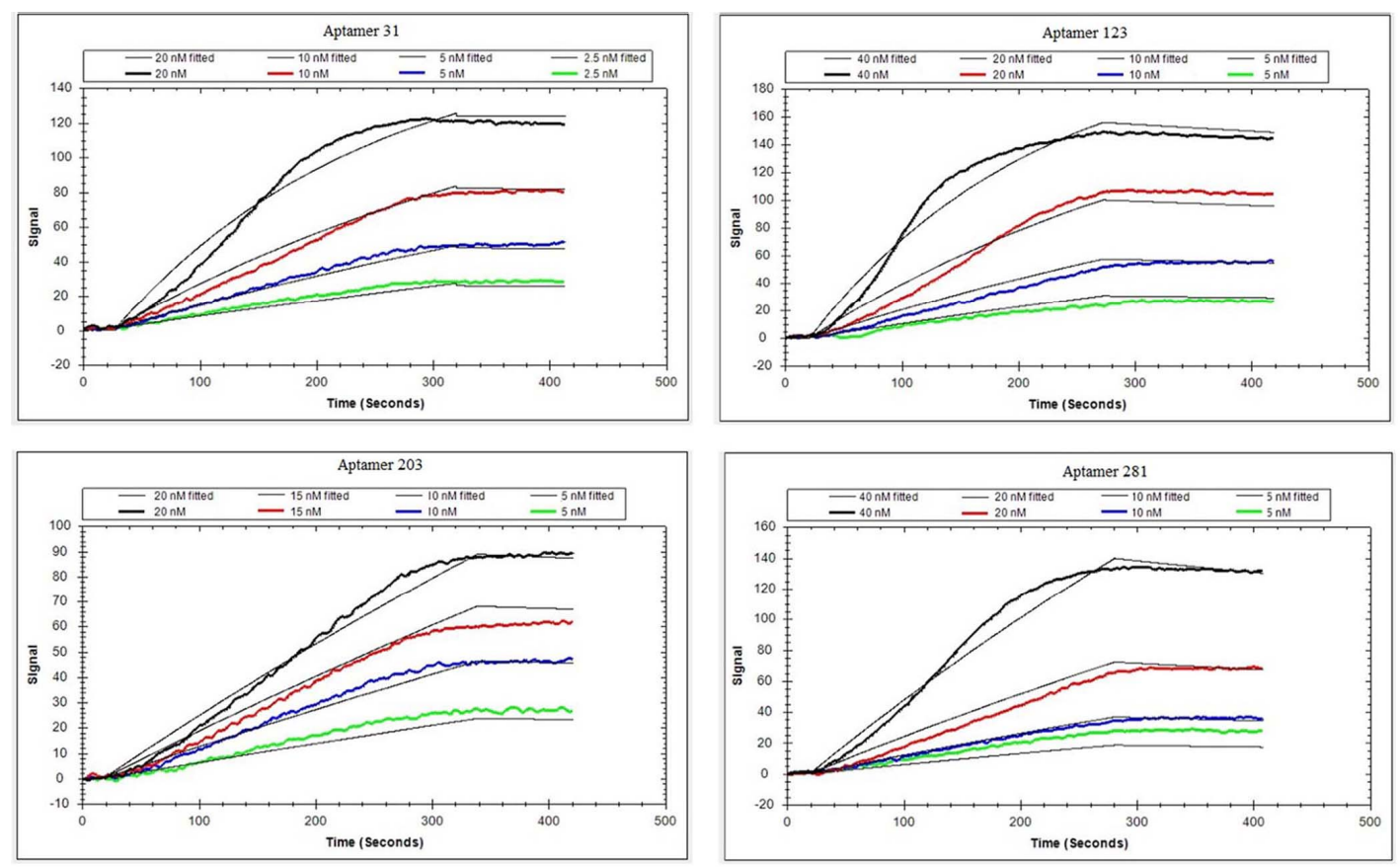

Figure 3. Binding kinetic curve of four aptamers interacting with di(2-ethylhexyl) phthalate (DEHP) by localized surface plasmon resonance (LSPR) assay. 
Table 1. Sequence $\left(5^{\prime}-3^{\prime}\right)$ and dissociation constant $(\mathrm{Kd})$ of aptamer candidates.

\begin{tabular}{ccc}
\hline Aptamer & \multicolumn{1}{c}{ Sequence $\mathbf{( 5}^{\prime} \mathbf{- 3}^{\prime} \mathbf{)}$} & $\mathbf{K d}(\mathbf{n M})$ \\
\hline 31 & ACGCATAGGGTGCGACCACATACGCCCCATGTATGTCCCTTGGTTGTGCCCTATGCGT & $2.26 \pm 0.06$ \\
123 & ACGCATAGGGCAACCAGACCAGCCCCATCCCCATGTGACTTCTGTTTGGCCTATGCGT & $5.33 \pm 0.01$ \\
203 & ACGCATAGGGCAAGACAAACTGCGCCATTCAGCATGCTGTTCGGGTTGGCCTATGCGT & $2.68 \pm 0.2$ \\
281 & ACGCATAGGGTGTGCATCAGCAGTACCAACGACGTTGTGGTGTGCTCATCCTATGCGT & $43 \pm 0.7$ \\
\hline
\end{tabular}

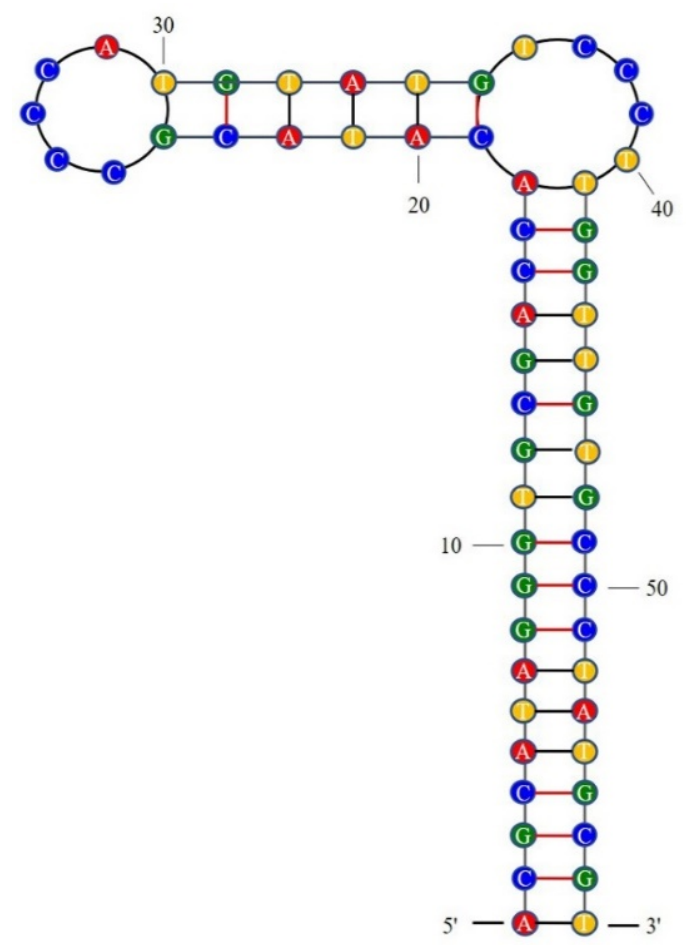

Figure 4. The secondary structure of aptamer 31.

\subsection{Fabrication of Electrochemical Impedance Spectroscope Aptasensor}

EIS is highly sensitive to surface changes, which allows biorecognition events to be measured with a simple and label-free strategy for rapid bioanalysis. Here, we immobilized the biomolecule onto the electrode and then adopted the impedance method to follow the surface step-by-step electron transfer resistance (Rct) changes [34]. The behavior of the EIS aptasensor is shown in Figure 5A. The bare gold electrode displayed the smallest Rct value, indicating the fastest electrode reaction process of $\left[\mathrm{Fe}(\mathrm{CN})_{6}\right]^{3-} /{ }^{4-}$ redox probes on conductive gold surface (curve a). The selected aptamer 31 was anchored on the gold electrode surface though $\mathrm{Au}-\mathrm{S}$ bond, with sulfhydryl modified on the end of the $5^{\prime}$ end. According to the EIS spectrum, the Rct value obviously increased (curve b) due to the obstacles to electron transfer. Two main factors could be ascribed to the increase of the semicircle that indicated the increase of Rct. On the one hand, the negative-charged sugar-phosphate backbone of the aptamer on the electrode surface prevented $\left[\mathrm{Fe}(\mathrm{CN})_{6}\right]^{3-} /{ }^{4-}$ from approaching the electrode surface due to strong electrostatic repulsion. On the other hand, the presence of the aptamer also partly blocked the electron/ion transport passageways between the electrode and the electrolyte. In addition, the immobilization of 6-mercapto-1-hexanol $(\mathrm{MCH})$ on the electrode surface further blocked the electron/ion transport passageways, and the modified electrode with the aptamer and MCH thus gave a much higher Rct response (curve c). When the previously modified electrode was successively incubated with DEHP, a continuous augmentation in the semicircle was observed (curve d). This might be because the binding of DEHP to the aptamer resulted in a significant conformational change of the aptamer on the electrode surface. This change amplified the coverage of the aptamer on the electrode surface and therefore further impeded the electron transfer efficiency. The electron transfer resistance 
increased with increasing concentration of DEHP. This result is consistent with a previous report [35], indicating an increase in electron transfer resistance with conformational change of aptamer.

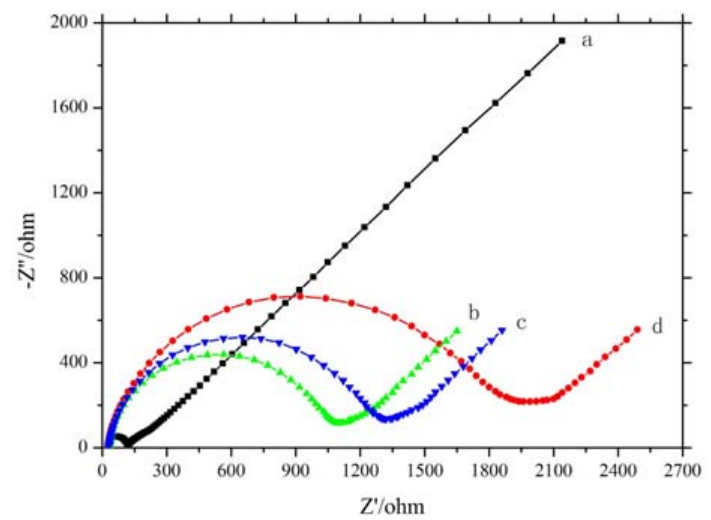

A

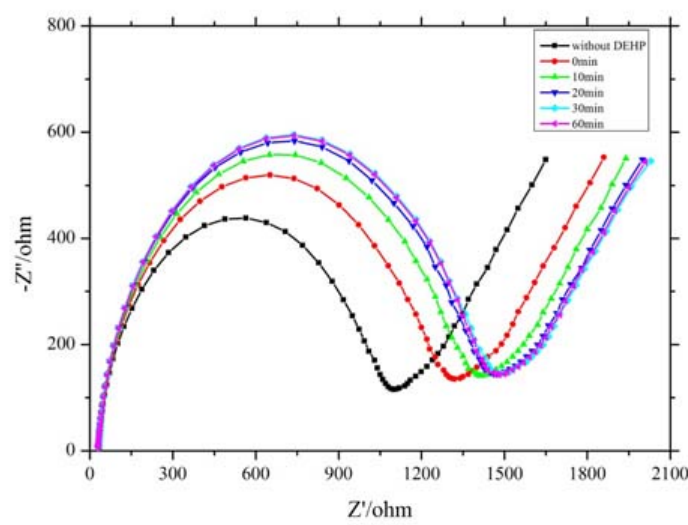

B

Figure 5. Electrochemical impedance spectroscopy (EIS) aptasensor. (A) Behavior of EIS aptasensor: (a) bare AuE, (b) aptamer 31 anchored on the gold electrode surface, (c) incubated with $\mathrm{MCH}$, (d) incubated with DEHP. (B) Optimization of the incubation time between DEHP and aptamer.

The optimal incubation time between DEHP and aptamer was explored to further improve the sensitivity, and the result is shown in Figure 5B. The EIS signal augmented during the incubation time from 0 to $30 \mathrm{~min}$, but no distinct change was observed when the incubation time was beyond $30 \mathrm{~min}$. Therefore, $30 \mathrm{~min}$ was deemed as the optimal incubation time between DEHP and aptamer. This result is in accordance with an earlier report that suggested $30 \mathrm{~min}$ incubation at room temperature [13].

\subsection{Analytical Application of Sulfhydryl Modified Aptamer 31 in DEHP Detection Using EIS Aptasensor}

The specificity of aptamer 31 was assessed, and the results are presented in Figure 6A. There was an obvious EIS signal when the detection target was DEHP, and the EIS signal decreased significantly when DEHP analogs were used as detection targets, clearly indicating that aptamer 31 had no cross-reactivity with DEHP analogs.

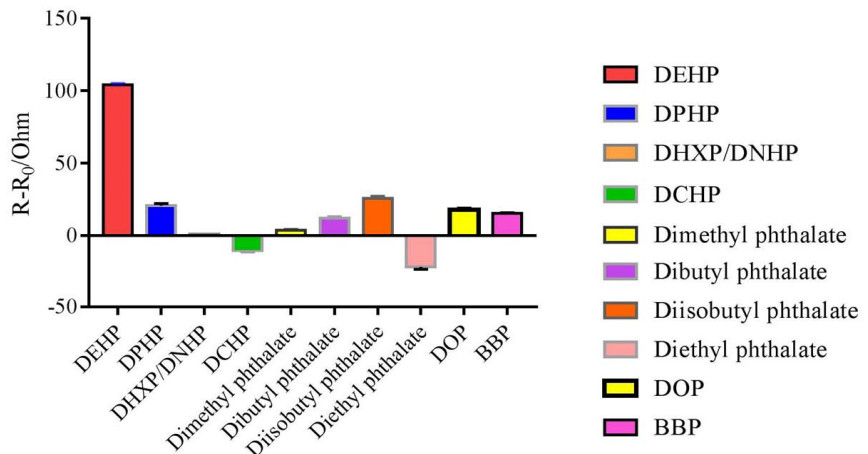

Figure 6. Specificity and sensitivity of EIS aptasensor. (A) Identification of the specificity of aptamer 31 against DEHP. The concentration of DEHP and analogs was 30.518 pg/mL. (B) Analytical curve of DEHP detection based on ultrasensitive EIS aptasensor.

The analytical curve for the interaction is shown in Figure 6B. The EIS signal intensity augmented sharply with the increase in DEHP. Consequently, the increased EIS intensity Rct revealed a desirable linear correlation with the logarithmic value of the DEHP concentration, fitted as $\Delta \mathrm{R}=29.42 \log (\mathrm{c})-$ $25.34\left(R^{2}=0.9973\right)$, where $\Delta \mathrm{R}$ and $\mathrm{c}$ represent the increased EIS signal and the DEHP concentration, respectively. The LOD was $0.103 \mathrm{pg} / \mathrm{mL}$, and the linear detection range was $7.629-2,000,000 \mathrm{pg} / \mathrm{mL}$. 
The LOD was lower than that reported in previous studies for the detection of DEHP, which were listed in Table 2. Moreover, the LOD also proved to be below the national standard of $1.5 \mu \mathrm{g} / \mathrm{mL}$, which was proposed in the GB9685-2008 for the use of additives for food containers and packaging materials. Therefore, the EIS aptasensor designed in this study exhibited high sensitivity and promising application for the detection of DEHP.

Table 2. Comparison of available methods for analysis of DEHP.

\begin{tabular}{|c|c|c|c|}
\hline Methods & Linear Range & Limit of Detection (LOD) & References \\
\hline High-performance liquid chromatography & $50-100,000 \mathrm{ng} / \mathrm{mL}$ & / & $5-7$ \\
\hline High-performance liquid chromatography-mass spectrometry & $0.01-0.1 \mathrm{ng} / \mathrm{mL}$ & $1 \mathrm{pg} / \mathrm{mL}$ & 8 \\
\hline Raman spectroscopy & $0.008-182 \mathrm{nM}$ & $3.12 \mathrm{pg} / \mathrm{mL}$ & 14 \\
\hline Enzyme-linked immunosorbent assay & $10^{-3}-10^{3} \mathrm{ng} / \mathrm{mL}$ & $4.2 \mathrm{pg} / \mathrm{mL}$ & 11 \\
\hline Multiresidue detection method based on aptamer & $0.5-30 \mathrm{ng} / \mathrm{mL}$ & $3.9 \mathrm{pg} / \mathrm{mL}$ & 12 \\
\hline An ultrasensitive electrochemical method & $7.629 \mathrm{pg} / \mathrm{mL}-2 \mu \mathrm{g} / \mathrm{mL}$ & $0.103 \mathrm{pg} / \mathrm{mL}$ & This work \\
\hline
\end{tabular}

To explore the application of EIS aptasensor, we used aptamer 31 for water analysis, and the results are presented in Table 3. The average recoveries were observed from $76.07 \%$ to $141.32 \%$ with the relative standard deviation (RSD) ranging from $0.55 \%$ to $2.74 \%$, indicating that the EIS aptasensor based on aptamer 31 is suitable for detection of DEHP residues in real samples.

Table 3. Recovery results of DEHP added in different water samples with the aptasensor.

\begin{tabular}{|c|c|c|c|c|}
\hline Samples & Spiked Concentration $\left(\mu \mathrm{g} \cdot \mathrm{L}^{-1}\right)$ & Detected Concentration $\left(\mu \mathrm{g} \cdot \mathrm{L}^{-1}\right)$ & RSD \% & Recovery \% \\
\hline \multirow{4}{*}{ Tap water } & 0.03 & 0.031 & 2.74 & 101.77 \\
\hline & 1.95 & 1.71 & 1.44 & 87.37 \\
\hline & 500 & 462.59 & 1.57 & 92.52 \\
\hline & 0.03 & 0.043 & 1.69 & 141.32 \\
\hline \multirow[t]{2}{*}{ Water from YB } & 1.95 & 1.73 & 2.50 & 88.50 \\
\hline & 500 & 488.44 & 2.54 & 97.69 \\
\hline \multirow{3}{*}{ Water from Qingshan Lake } & 0.03 & 0.026 & 2.15 & 85.70 \\
\hline & 1.95 & 1.49 & 2.19 & 76.07 \\
\hline & 500 & 481.22 & 0.55 & 96.24 \\
\hline
\end{tabular}

\section{Materials and Methods}

\subsection{Chemicals and Reagents}

The DEHP standards and analogs were purchased from TMRM Ltd. (Beijing, China). Taq polymerase, dNTPs, and 2x TBE-urea buffer were purchased from Sangon Biotech Ltd. (Shanghai, China). Dynabeads ${ }^{\mathrm{TM}}$ MyOne ${ }^{\mathrm{TM}}$ Streptavidin $\mathrm{T} 1$ were purchased from Thermo Fisher Scientific Ltd. (Shanghai, China). $\mathrm{HAuCl}_{4} \cdot 4 \mathrm{H}_{2} \mathrm{O}$ was purchased from Sinopharm Chemical Reagent Co., Ltd. (Shanghai, China). EvaGreen was purchased from Shanghai Open Biotechnology Ltd. (Shanghai, China). All other reagents were purchased from Sinopharm Chemical Reagents Ltd. (Shanghai, China). The aptamer library was synthesized by Sangon Biotech Ltd. (Shanghai, China). The primers in Table S1, according to our previous report [36], were synthesized by Nanjing Genscript Biotechnology Ltd. (Nanjing, China). The aptamers were synthesized from Suzhou Hongxun Biotechnology Ltd. (Suzhou, China). HTS was performed by Anhui Angputuomai Biotechnology Ltd. (Hefei, China). Secondary structures were calculated with mfold online bioinformatics platforms (http://unafold.rna.albany.edu/?q=mfold/DNA-Folding-Form). EIS aptasensor was performed on the CHI660E electrochemical workstation from Shanghai Chinstruments Ltd. (Shanghai, China). Milli-Q water was used for preparing all of the buffers and solutions.

\subsection{Selection of Aptamers Specific for DEHP Based on SSDNA library immobilized SELEX}

The ssDNA library immobilized SELEX was established to select aptamers specific for DEHP, and the process of selection is shown in the graphical abstract (Figure 7). The 1.3 nM ssDNA library 
(5'-ATTGGCACTCCACGCATAGG(N) ${ }_{40}$ CCTATGCGTGCTACCGTGAA-3') was dissolved in $520 \mu \mathrm{L}$ DPBS buffer $\left(0.1 \mathrm{~g} \mathrm{CaCl}_{2}, 0.2 \mathrm{~g} \mathrm{KCl}, 0.2 \mathrm{~g} \mathrm{KH}{ }_{2} \mathrm{PO} 4,0.1 \mathrm{~g} \mathrm{MgCl}_{2} .6 \mathrm{H}_{2} \mathrm{O}, 8 \mathrm{~g} \mathrm{NaCl}\right.$, and $1.15 \mathrm{~g} \mathrm{Na}_{2} \mathrm{HPO}_{4}$; $1 \mathrm{~L}, \mathrm{pH} 7.5)$. A volume of $26 \mu \mathrm{L}$ Biotin-P (100 $\mu \mathrm{M}$ in DPBS, pH 7.5) was added to the dissolved library at a molar ratio of 2:1 through the procedure of denaturation and renaturation at $95^{\circ} \mathrm{C}$ for $10 \mathrm{~min}, 60^{\circ} \mathrm{C}$ for $1 \mathrm{~min}$, and $25^{\circ} \mathrm{C}$ for $1 \mathrm{~min}$. The obtained mixture was mixed with $700 \mu \mathrm{L}$ streptavidin magnetic beads $\left(7-10 \times 10^{9}\right.$ beads $\left./ \mathrm{mL}\right)$ that were first washed 4 times with the DPBS buffer in the first round of selection. After incubating for $45 \mathrm{~min}$ at room temperature, the magnetic beads were washed 6 times and then incubated for 90 min with DEHP in $200 \mu \mathrm{L}$ binding buffer to a final concentration of $100 \mu \mathrm{M}$. The supernatant was collected by magnetic separation. The magnetic beads were again washed with $200 \mu \mathrm{L}$ binding buffer, and the supernatant was collected. The above supernatant was mixed as the eluent library with a volume of $400 \mu \mathrm{L}$ in total.

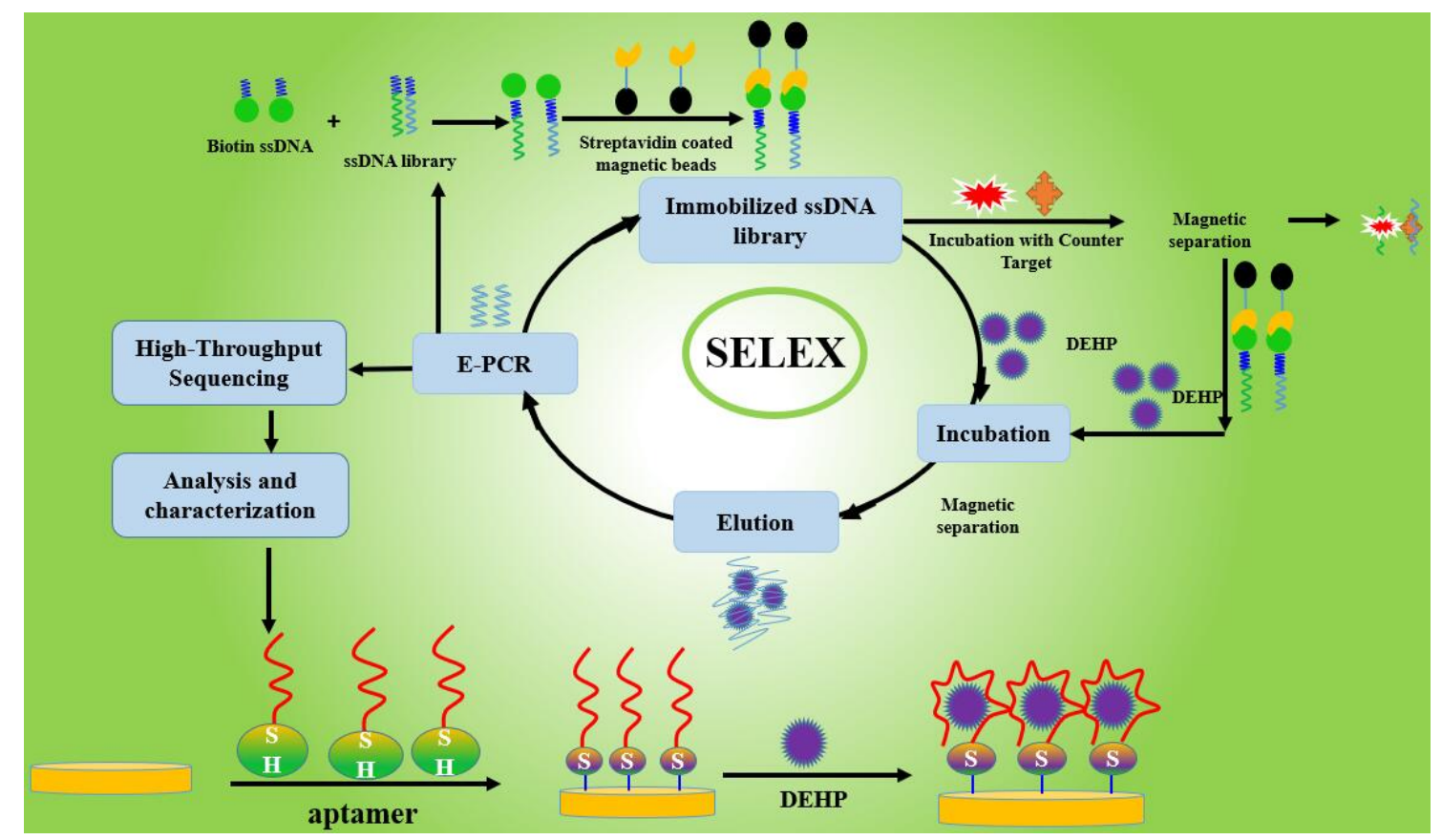

Figure 7. Graphical abstract.

\subsection{Establishment of a Real-Time Quantitative PCR Method for the Monitoring Selection Process}

The initial ssDNA library with a series of concentrations $(16,000,1600,160,16$, and $1.6 \mathrm{pM})$ was used as a template in real-time Q-PCR. During this process, $2 \mu \mathrm{L}$ of template was added into a $30 \mu \mathrm{L}$ Q-PCR mix. The mix consisted of $1 \mu \mathrm{L}$ Q-Forward at a concentration of $10 \mu \mathrm{M}, 1 \mu \mathrm{L}$ Q-Reverse at a concentration of $10 \mu \mathrm{M}, 0.5 \mu \mathrm{L}$ dNTP mix at a concentration of $10 \mathrm{mM}, 3 \mu \mathrm{L} 10 \times \mathrm{PCR}$ buffer, $1 \mu \mathrm{L}$ Taq DNA polymerase, and $1 \mu \mathrm{L}$ EvaGreen, with sterile water added to make a final volume of $30 \mu \mathrm{L}$. The Q-PCR procedure (StepOnePlus purchased from ABI in the USA) was adopted with the condition of $95{ }^{\circ} \mathrm{C}$ for $2 \mathrm{~min}, 95^{\circ} \mathrm{C}$ for $0.5 \mathrm{~min}, 60^{\circ} \mathrm{C}$ for $0.5 \mathrm{~min}$, and $72{ }^{\circ} \mathrm{C}$ for $0.5 \mathrm{~min}$; there were 30 cycles in total. The analytical curve of Q-PCR was prepared using Ct value as an ordinate and logarithm DNA concentration of the template as an abscissa. The Q-PCR amplification was used to monitor the enrichment of libraries with the $2 \mu \mathrm{L}$ eluent library as the template from each round of selection.

\subsection{Preparation of Secondary Libraries}

After each round of selection, all of the eluent library ( $398 \mu \mathrm{L}$ template DNA) was mixed with $2 \mathrm{~mL}$ emulsion PCR mix that consisted of $10 \mu \mathrm{L}$ FAM-Forward at a concentration of $100 \mu \mathrm{M}, 10 \mu \mathrm{L}$ polyA-Reverse at a concentration of $100 \mu \mathrm{M}, 40 \mu \mathrm{L}$ dNTP mix at a concentration of $10 \mathrm{mM}, 200 \mu \mathrm{L}$ $10 \times$ PCR buffer, $8 \mu \mathrm{L}$ Taq DNA polymerase, and $1732 \mu \mathrm{L}$ sterile water. Then, the $8 \mathrm{~mL}$ emulsifier 
(1 mL EM 90, $25 \mu \mathrm{L}$ triton X-100, and $49 \mathrm{~mL}$ mineral oil) was added. After vortexing for $2 \mathrm{~min}$, it was stood for $5 \mathrm{~min}$. The PCR proceeded at $95{ }^{\circ} \mathrm{C}$ for $2 \mathrm{~min}, 95{ }^{\circ} \mathrm{C}$ for $1 \mathrm{~min}, 60{ }^{\circ} \mathrm{C}$ for $1 \mathrm{~min}$, and $72{ }^{\circ} \mathrm{C}$ for $1 \mathrm{~min}$ for 25 cycles. The PCR product was concentrated with n-butyl alcohol. Then, it was mixed with $2 \times$ TBE-urea buffer and separated at denatured SDS-PAGE (400 V, $15 \mathrm{~min})$. The separated fluorescent strip was cut off and boiled to isolate the secondary ssDNA library. It was dialyzed using a $1.5 \mathrm{~mL}$ tube cover and dialysis membrane in binding buffer overnight. The concentration of the secondary library was measured at $260 \mathrm{~nm}$, and the secondary library was used to select specific aptamers in the next round of selection. The process of selection from the first to fourth round was the same, and the selections from the fifth to the eighth round were the counter selection with mixed analogs (diphenyl phthalate (DPHP), dihexyl phthalate (DHXP/DNHP), dicyclohexyl phthalate (DCHP), dimethyl phthalate, dibutyl phthalate, diisobutyl phthalate, diethyl phthalate, di-n-octylo phthalate (DOP), butyl benzyl phthalate (BBP)) and positive selection with DEHP. In the first round of selection, the amount of ssDNA library was $1.3 \mathrm{nM}$. However, in the other rounds, the amount of ssDNA library was $100 \mathrm{pM}$.

\subsection{High-Throughput Sequencing and Sequence Analysis of the Enriched Library}

The enriched library at the eighth round was sent to Anhui Angputuomai Biotechnology Co., Ltd. for HTS on an Illumina PE150 HTS platform. Three hundred sequences with higher frequency of occurrence were selected from the HTS results. Homologous comparison of these three hundred sequences was carried out using clustalX2 software. The comparison was then analyzed by TreeView tool version 1.6.6, and one hundred and twenty-nine sequences with a high homology rate were selected for further analysis. The secondary structure was predicted using mfold online bioinformatics platforms (http://unafold.rna.albany.edu/?q=mfold/DNA-Folding-Form). Ninety-six sequences with $\geq 2$ ring regions and the high frequency of occurrence were selected. Each aptamer was cut with 11 bases each from the $5^{\prime}$ and $3^{\prime}$ constant regions, and the 58 bases remaining were then synthesized.

\subsection{Determination of Binding Activity Between Aptamers and DEHP Using a Gold Nanoparticles Colomertric Assay}

A AuNPs colorimetric assay was used to preliminarily determine the binding activity of candidate unmodified aptamers. AuNPs were prepared by reducing chloroauric acid with sodium citrate as in a previous report [37]. The AuNPs solution was centrifuged at 12,000 r/min and dissolved in ultrapure water. The concentration of AuNPs $(8.76 \mathrm{nM})$ was determined using UV-vis spectroscopy according to a previously reported method [38]. Firstly, $50 \mu \mathrm{L} /$ well of aptamers with a concentration of $0.4 \mu \mathrm{M}$ were incubated with $1 \mu \mathrm{g} / \mathrm{mL}$ DEHP (50 $\mu \mathrm{L} /$ well) for $30 \mathrm{~min}$. AuNPs (50 $\mu \mathrm{L} /$ well, 8.76 nM) were mixed and incubated for $30 \mathrm{~min}$, and $1.0 \mathrm{M} \mathrm{NaCl}(10 \mu \mathrm{L} /$ well $)$ was then added at room temperature. The absorbance values at $620 \mathrm{~nm}\left(\mathrm{~A}_{620 \mathrm{~nm}}\right)$ and $520 \mathrm{~nm}\left(\mathrm{~A}_{520 \mathrm{~nm}}\right)$ were measured on an automatic microplate reader (I3X, Molecular Devices, USA). The binding activity of aptamers was determined by the ratio of $A_{620 \mathrm{~nm}} / \mathrm{A}_{520 \mathrm{~nm}}$ between the experimental group $(A)$ and the blank group $\left(\mathrm{A}_{0}\right)$.

\subsection{Affinity Analysis of Active Aptamers Using LSPR}

The LSPR was used to determine affinity of aptamers on an OpenSPRTM (Nicoya Lifesciences, Waterloo, Canada). The specific steps were as follows. First, $100 \mu \mathrm{g}$ DEHP modified with carboxyl group (Figure 8) was fixed to the $\mathrm{NH}_{2}$ chip through $\mathrm{NH}_{2}$ and $\mathrm{COOH}$ interaction and then blocked with $1 \mathrm{M}$ ethanolamine ( $\mathrm{pH}$ 8.5). After the baseline was adjusted with phosphate buffer solution (PBS, $\left.29.2 \mathrm{~g} \mathrm{NaCl}, 0.69 \mathrm{~g} \mathrm{NaH}_{2} \mathrm{PO}_{4}, 0.71 \mathrm{~g} \mathrm{Na}_{2} \mathrm{HPO}_{4}, 0.1 \mathrm{~g} \mathrm{MgCl} \cdot 6 \mathrm{H}_{2} \mathrm{O} ; 500 \mathrm{~mL}, \mathrm{pH} 7.0\right)$, aptamers (31, 123, $203,281)$ diluted to different concentrations $(2.5,5,10$, and 20 or $5,10,20$, and $40 \mathrm{nM})$ were allowed to bind with DEHP for 240s. The flowrate was $20 \mu \mathrm{L} / \mathrm{min}$, and the chip was regenerated with 5-10 mM $\mathrm{NaOH}$. The analysis software used in this experiment was TraceDrawer (Ridgeview Instruments ab, Sweden) using one-to-one analysis model [39]. 


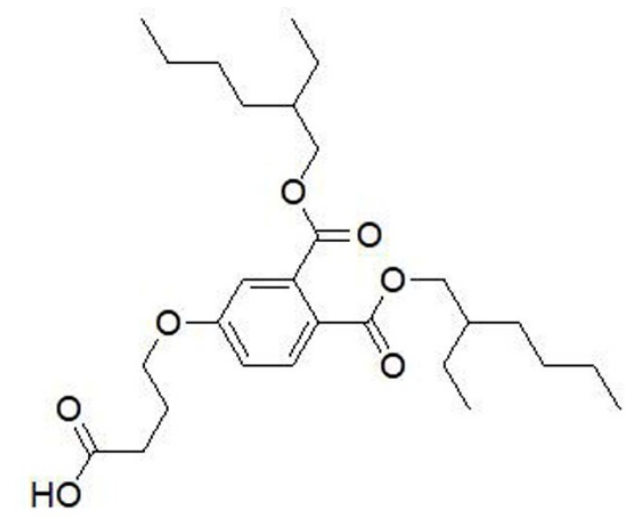

Figure 8. Structure of carboxy-modified DEHP.

\subsection{Fabrication of EIS Aptasensor}

The procedures of electrode pretreatment and modification were as follows. After polishing successively with 0.3 and $0.05 \mu \mathrm{m}$ alumina, the gold electrodes ( $\mathrm{AuE}, \Phi=3 \mathrm{~mm}, \mathrm{CHI}$ ) were washed with four steps in $0.5 \mathrm{M} \mathrm{NaOH}, 0.5 \mathrm{M} \mathrm{H}_{2} \mathrm{SO}_{4}, 0.1 \mathrm{M} \mathrm{H}_{2} \mathrm{SO}_{4}$ with $0.01 \mathrm{M} \mathrm{KCl}$, and $0.05 \mathrm{M} \mathrm{H}_{2} \mathrm{SO}_{4}$ respectively, and then scanned by the cyclic voltammetry method. They were then thoroughly washed ultrasonically in ethanol and distilled water. Then, $2 \mu \mathrm{L}$ of sulfhydryl modified aptamer $(1 \mu \mathrm{M})$ was added into $2 \mu \mathrm{L}$ activation solution ( $3 \mathrm{mg}$ tris(2-carboxyethyl)phosphine (TCEP) in $100 \mu \mathrm{L}$ PBS buffer) to open the disulfide bond formed by sulfhydryl groups between DNA for $1 \mathrm{~h}$. After mixing with $10 \mathrm{mM}$ PBS ( $\mathrm{pH}=7.0$ ), the total volume reached $200 \mu \mathrm{L}$, and it was immediately suspended on the surface of the electrode to be incubated for $16 \mathrm{~h}$. The surface of the electrode was then washed with PBS and subsequently immersed into a $0.5 \mathrm{~mL} \mathrm{MCH}$ solution $(2 \mathrm{mM})$ for $5 \mathrm{~h}$ to avoid nonspecific binding of other molecules and then finally washed with PBS buffer. EIS was carried out using a CHI 660E electrochemistry workstation (Shanghai, China) in PBS containing $10 \mathrm{mM} \mathrm{K}_{3}\left[\mathrm{Fe}(\mathrm{CN})_{6}\right] / \mathrm{K}_{4}\left[\mathrm{Fe}(\mathrm{CN})_{6}\right]$ (1:1) mixture and $0.5 \mathrm{M} \mathrm{KCl}$ as the supporting electrolyte with a conventional three-electrode system comprising a platinum wire as the auxiliary electrode, an $\mathrm{Ag} / \mathrm{AgCl}$ as the reference electrode, and the modified $\mathrm{AuE}$ as the working electrode. The impedance spectra were recorded within the frequency range of $10^{-2}-10^{5} \mathrm{~Hz}$ and AC amplitude of $5 \mathrm{mV}$. The surface behaviors of the electrode were studied, and the incubation time $(0,10,20,30$, and $60 \mathrm{~min})$ was optimized between the aptasensor and DEHP. The classical three-electrode system was used for EIS measurements. The $\mathrm{Ag} / \mathrm{AgCl}$ electrode (saturated $\mathrm{KCl}$ ), a platinum wire, and bare or modified gold electrode ( $3 \mathrm{~mm}$ in diameter) were used as reference electrode, counter electrode, and working electrode, respectively.

\subsection{Specificity and Sensitivity Analysis of Aptamer 31}

The pretreatment and modification of gold electrodes (AuE, $\Phi=3 \mathrm{~mm}, \mathrm{CHI})$ were carried out as mentioned above. The cross-reactivity (sulfhydryl modified aptamers incubated with DEHP analogs) was designed using DEHP and DEHP analogs (DPHP, DHXP/DNHP, DCHP, DOP, BBP, dimethyl phthalate, dibutyl phthalate, diisobutyl phthalate, diethyl phthalate) as detection targets with the concentration of $30.518 \mathrm{pg} / \mathrm{mL}$ at the optimal incubation time. The target was added to the supporting electrolyte of $10 \mathrm{mM} \mathrm{K}_{3}\left[\mathrm{Fe}(\mathrm{CN})_{6}\right] / \mathrm{K}_{4}\left[\mathrm{Fe}(\mathrm{CN})_{6}\right](1: 1)$ mixture with $0.5 \mathrm{M} \mathrm{KCl}$ (pH 7.0) in PBS buffer. The impedance was detected, and the cross-reactivity was indicated by $\Delta \mathrm{R}$.

For the analytical curve, the pretreatment and modification of gold electrodes (AuE, $\Phi=3 \mathrm{~mm}$, $\mathrm{CHI})$ were carried out as mentioned above. The DEHP standard solution $(1 \mu \mathrm{L})$ with different concentrations $(7.629,30.518,122.07,488,1953,7813,31,250,125,000,500,000$, and 2,000,000 pg/mL) was added to the supporting electrolyte of $10 \mathrm{mM} \mathrm{K}_{3}\left[\mathrm{Fe}(\mathrm{CN})_{6}\right] / \mathrm{K}_{4}\left[\mathrm{Fe}(\mathrm{CN})_{6}\right](1: 1)$ mixture with $0.5 \mathrm{M}$ $\mathrm{KCl}$ (pH 7.0) in PBS buffer. The impedance was detected, and $\triangle \mathrm{R}$ was used as ordinate and log (DEHP concentration) as an abscissa. 


\subsection{Application of the EIS Aptasensor in Spiked Water Samples}

The samples were collected from Qingshan Lake, tap water, and YB water. The DEHP standard was added to the water samples (negative samples) to obtain different final concentrations (30, 1950, and 500,000 pg/mL). Samples $(1 \mu \mathrm{L})$ were added to the supporting electrolyte of $10 \mathrm{mM}$ $\mathrm{K}_{3}\left[\mathrm{Fe}(\mathrm{CN})_{6}\right] / \mathrm{K}_{4}\left[\mathrm{Fe}(\mathrm{CN})_{6}\right]$ (1:1) mixture with $0.5 \mathrm{M} \mathrm{KCl}(\mathrm{pH} 7.0)$ in PBS buffer. The impedance was detected under the optimal conditions (aptamer concentration of $0.01 \mu \mathrm{M}$, incubation time of $30 \mathrm{~min}$ ), and the recovery was calculated.

\section{Conclusions}

Aptamers are functional molecules that can substitute antibodies in the development of rapid detection methods. In this research, the bottleneck problem was to select an aptamer specific for DEHP and to design a direct DEHP detection method for improving sensitivity and affinity. We proposed a rapid selection and identification strategy, which included Q-PCR monitoring, high- throughput sequencing, a AuNPs colomertric assay, and LSPR. After the eighth round of selection, the retention rate was about $14 \%$. Four aptamers had high binding activity, and aptamer 31 had the highest affinity $(\mathrm{Kd}=2.26 \pm 0.06 \mathrm{nM})$. Then, the EIS aptasensor was used to detect water samples with a mean recovery of $76.07 \%$ to $141.32 \%$. In this study, a novel aptamer specific for DEHP was selected, and a direct DEHP detection method based on an electrochemical aptasensor with ultrasensitivity was developed for low-cost, rapid, and sensitive detection. Most importantly, the rapid selection and identification strategy proposed in this study decreased the cost, complexity, and difficulty of the experiment. As a universal technical method, it can be used for the selection and identification of other aptamers specific for small molecules.

\section{Patents}

Liu, X.X.; Hou, J.J.; Lu, Q.; Yuan Q.X. An aptamer used to detect DEHP and its screening method and application. Patent 2019, application number: 201910547712.8

Supplementary Materials: Table S1. Primer sequences; Figure S1. The 300 sequences with a greater frequency of occurrence from high-throughput sequencing; Figure S2. Phylogenetic tree analysis of 300 sequences; Retention rate formulas.

Author Contributions: Conceptualization, X.L. and Q.L.; methodology, Q.L. and Q.Y.; software, Q.L., S.C., and Y.L.; validation, X.L.; formal analysis, X.L.; data curation, Q.L.; writing-original draft preparation, Q.L. and X.L.; writing-review and editing, X.L.; supervision, J.H.; project administration, J.H.; funding acquisition, X.L. All authors have read and agreed to the published version of the manuscript.

Funding: This research was funded by the National Natural Science Foundation of China (No. 31601548), Hubei Youth Science and Technology Morning Light Program (No. 2019), the Research Fund for Science and Technology Innovation Team of Hubei Normal University (No. T201504), and Central Committee Guides Local Science and Technology Development Project (No. 2017ZYYD008).

Conflicts of Interest: The authors declare no conflict of interest.

\section{References}

1. Melnick, R.L. Is peroxisome proliferation an obligatory precursor step in the carcinogenicity of Di (2-ethylhexyl) phthalate (DEHP)? Environ. Health Perspect. 2001, 109, 437-442. [CrossRef] [PubMed]

2. Saillenfait, A.M.; Langonne, I.; Leheup, B. Effects of mono-n-butyl phthalate on the development of rat embryos: In vivo and in vitro observations. Toxicol. Appl. Pharm. 2001, 89, 104-112. [CrossRef] [PubMed]

3. How, C.M.; Yen, P.L.; Wei, C.C.; Li, S.W.; Liao, V.H.C. Early life exposure to di (2-ethylhexyl) phthalate causes age-related declines associated with insulin/IGF-1-like signaling pathway and SKN-1 in Caenorhabditis elegans. Environ. Pollut. 2019, 251, 871-878. [CrossRef] [PubMed]

4. Azevedo, R.; Oliveira, N.; Maia, C.; Verde, I. Effects of di(2-etilhexil) phthalate on human umbilical artery. Chemosphere 2019, 228, 278-286. [CrossRef] 
5. Aignasse, M.F.; Prognon, P.; Stachowicz, M.; Gheyouche, R.; Pradeau, D. A new simple and rapid HPLC method for determination of DEHP in PVC packaging and releasing studies. Int. J. Pharm. 1995, 113, 241-246. [CrossRef]

6. Deng, L.; Wu, F.; Deng, N.S.; Yang, Y. Determination of trace DEHP in aqueous solution by solid phase microextraction coupled with high performance liquid chromatography. Fresen. Environ. Bull. 2005, 14, 494-497.

7. Li, B.P.; Lin, Q.B.; Song, H.; Li, L.L. Determination of DEHP and DNOP in PVC film by ASE-RP-HPLC. Chin. J. Appl. Chem. 2008, 25, 63-66.

8. Pinguet, J.; Kerckhove, N.; Eljezi, T.; Lambert, C.; Moreau, E.; Bernard, L.; Boeuf, B.; Decaudin, B.; Genay, S.; Masse, M.; et al. New SPE-LC-MS/MS method for the simultaneous determination in urine of 22 metabolites of DEHP and alternative plasticizers from PVC medical devices. Talanta 2019, 198, 377-389. [CrossRef]

9. Cai, Z.M.; Zhang, Q.L.; Zhao, W.H.; Yang, K.F.; Wang, L.P.; Luo, N.; Tan, L.T. GC-MS determination of phthalates (DBP and DEHP) dissolved from plastic bags. Phys. Test. Chem. Anal. B 2003, 39, 529-530.

10. Liang, D.P.; Fang, Y.P.; Liu, W.J.; Zhang, H.; Qiu, Y.T.; Dong, Y.M.; Ning, Y. Direct determination of bis (2-ethylhexyl) phthalate in environmental water samples by electrospray extraction ionization mass spectrometry. Chin. J. Anal. Chem. 2018, 46, 883-888.

11. Zhang, M.; Hong, W.; Wu, X.; Zhang, Y.; Li, F.; Zhao, S.Q. A highly sensitive and direct competitive enzyme-linked immunosorbent assay for the detection of di-(2-ethylhexyl) phthalate (DEHP) in infant supplies. Anal. Methods UK 2015, 7, 5441-5446. [CrossRef]

12. Han, Y.; Diao, D.L.; Lu, Z.W.; Li, X.N.; Guo, Q.; Huo, Y.M.; Xu, Q.; Li, Y.S.; Cao, S.L.; Wang, J.C.; et al. Selection of group-specific PAE-binding DNA aptamers via rational designed target immobilization and applications for ultrasensitive and highly selective detection of PAEs. Anal. Chem. 2017, 89, 5270-5277. [CrossRef]

13. Lim, H.J.; Kim, A.R.; Yoon, M.Y.; You, Y.; Chua, B.; Son, A. Development of quantum dot aptasensor and its portable analyzer for the detection of di-2-ethylhexyl phthalate. Biosens. Bioelectron. 2018, 121, 1-9. [CrossRef]

14. Tu, D.D.; Garza, T.J.; Coté, L.G. A SERS aptasensor for sensitive and selective detection of bis(2-ethylhexyl) phthalate. Rsc Adv. 2019, 9, 2618-2625. [CrossRef] [PubMed]

15. Bird, R.E.; Walker, B.W. Single chain antibody variable regions. Trends Biotechnol. 1991, 9, 132-137. [CrossRef]

16. Zhong, W.; Pu, Y.; Tan, W.H.; Liu, J.; Liao, J.; Liu, B.; Chen, K.; Yu, B.; Hu, Y.L.; Deng, Y.Y. Identification and application of an aptamer targeting papillary thyroid carcinoma using tissue-SELEX. Anal. Chem. 2019, 91, 8289-8297. [CrossRef] [PubMed]

17. Shao, N.S.; Li, S.H.; Huang, Y.P. New development of SELEX technology and aptamer research. Prog. Biochem. Biophys. 2006, 33, 329-335.

18. Gong, S.; Wang, Y.L.; Wang, Z.; Sun, Y.Y.; Zhang, W.B. Folding behaviors of purine riboswitch aptamers. Wuhan Univ. J. Nat. Sci. 2018, 23, 43-50. [CrossRef]

19. Shen, R.; Tang, J.J.; Zhang, Z.Y.; Guo, L.; Xie, J.W. New magnetic beads-based enzyme linked aptamer colorimetric assay for trace amount protein detection. Chem. Res. Chin. Univ. 2009, 4, 701-705.

20. Duan, N.; Gong, W.H.; Wu, S.J.; Wang, Z.P. An ssDNA library immobilized SELEX technique for selection of an aptamer against ractopamine. Anal. Chim. Acta 2017, 961, 100-105. [CrossRef]

21. Beheshti-Marnani, A.; Hatefi-Mehrjardi, A.; Es'haghi, Z. A sensitive biosensing method for detecting of ultra-trace amounts of AFB1 based on "Aptamer/reduced graphene oxide" nano-bio interaction. Colloids Surf. B 2019, 175, 98-105. [CrossRef] [PubMed]

22. Lu, J.H.; Tan, S.Z.; Zhu, Y.Q.; Li, W.; Chen, T.X.; Wang, Y.; Liu, C. Fluorescent aptamer functionalized graphene oxide biosensor for rapid detection of chloramphenicol. Acta. Chim. Sin. 2019, 77, 253-256. [CrossRef]

23. Bianco, M.; Sonato, A.; De Girolamo, A.; Pascale, M.; Romanato, F.; Rinaldi, R.; Arima, V. An aptamer-based SPR-polarization platform for high sensitive OTA detection. Sens. Actuat. B Chem. 2017, 241, 314-320. [CrossRef]

24. Luo, Z.F.; He, L.; Wang, J.J.; Fang, X.N.; Zhang, L.Y. Developing a combined strategy for monitoring the progress of aptamer selection. Analyst 2017, 142, 3136-3139. [CrossRef]

25. Lee, A.Y.; Ha, N.R.; Jung, I.P.; Kim, S.H.; Kim, A.R.; Yoon, M.Y. Development of a ssDNA aptamer for detection of residual benzylpenicillin. Anal. Biochem. 2017, 531, 1-7. [CrossRef] 
26. Challier, L.; Mavre, F.; Moreau, J.; Fave, C.; Schollhorn, B.; Marchal, D.; Peyrin, E.; Noel, V.; Limoges, B. Simple and highly enantioselective electrochemical aptamer-based binding assay for trace detection of chiral compounds. Anal. Chem. 2012, 84, 5415-5420. [CrossRef]

27. Li, J.; Zhong, X.; Zhang, H.; Le, X.C.; Zhu, J.J. Binding-induced fluorescence turn-on assay using aptamer-functionalized silver nanocluster DNA probes. Anal. Chem. 2012, 84, 5170-5174.

28. Gopinath, S.C.B.; Lakshmipriya, T.; Awazu, K. Colorimetric detection of controlled assembly and disassembly of aptamers on unmodified gold nanoparticles. Biosens. Bioelectron. 2014, 51, 115-123. [CrossRef]

29. Yoo, S.M.; Kim, D.K.; Lee, S.Y. Aptamer-functionalized localized surface plasmon resonance sensor for the multiplexed detection of different bacterial species. Talanta 2015, 132, 112-117. [CrossRef]

30. Li, S.Y.; Chen, D.Y.; Zhou, Q.T.; Wang, W.; Gao, L.F.; Jiang, J.; Cui, H. A general chemiluminescence strategy for measuring aptamer-target binding and target concentration. Anal. Chem. 2014, 86, 5559-5566.

31. Rangel, A.E.; Chen, Z.; Ayele, T.M.; Heemstra, J.M. In vitro selection of an XNA aptamer capable of small-molecule recognition. Nucleic Acids Res. 2018, 46, 8057-8068. [CrossRef] [PubMed]

32. Wu, Y.G.; Zhan, S.S.; Wang, L.M.; Zhou, P. Selection of a DNA aptamer for cadmium detection based on cationic polymer mediated aggregation of gold nanoparticles. Analyst 2014, 139, 1550-1561. [CrossRef] [PubMed]

33. Zhang, H.H.; Yang, S.; Zhou, Q.; Yang, L.K.; Wang, P.J.; Fang, Y. The suitable condition of using LSPR model in SERS: LSPR effect versus chemical effect on microparticles surface-modified with nanostructures. Plasmonics 2017, 12, 77-81. [CrossRef]

34. Kharitonov, A.B.; Alfonta, L.; Katz, E.; Willner, I. Probing of bioaffinity interactions at interfaces using impedance spectroscopy and chronopotentiometry. Electroanal. Chem. 2000, 487, 133-141. [CrossRef]

35. Zhou, N.D.; Luo, J.B.; Zhang, J.; You, Y.D.; Tian, Y.P. A label-free electrochemical aptasensor for the detection of kanamycin in milk. Anal. Methods 2015, 7, 1991. [CrossRef]

36. Liu, X.X.; Lu, Q.; Chen, S.R.; Wang, F.; Hou, J.J.; Xu, Z.L.; Meng, C.; Hu, T.Y.; Hou, Y.Y. Selection and identification of novel aptamers specific for clenbuterol based on ssDNA library Immobilized SELEX and gold nanoparticles colomertric assay. Molecules 2018, 23, 2337. [CrossRef]

37. Yao, X.; Ma, X.D.; Ding, C.; Jia, L. Colorimetric determination of lysozyme based on the aggregation of gold nanoparticles controlled by a cationic polymer and an aptamer. Microchim. Acta 2016, 183, 2353-2359. [CrossRef]

38. Haiss, W.; Thanh, N.T.K.; Aveyard, J.; Fernig, D.G. Determination of size and concentration of nanoparticles from UV-Vis spectra. Anal. Chem. 2007, 79, 4215-4221. [CrossRef]

39. Lu, Y.; Xu, X.; Jiang, T.; Jin, L.; Zhao, X.D.; Cheng, J.H.; Jin, X.J.; Ma, J.; Piao, H.N.; Piao, L.X. Sertraline ameliorates inflammation in CUMS mice and inhibits TNF-alpha-induced inflammation in microglia cells. Int. Immunopharmacol. 2019, 67, 119-128. [CrossRef]

Sample Availability: Samples of the compounds are not available from the authors.

(C) 2020 by the authors. Licensee MDPI, Basel, Switzerland. This article is an open access article distributed under the terms and conditions of the Creative Commons Attribution (CC BY) license (http://creativecommons.org/licenses/by/4.0/). 